\title{
Caso clínico radiológico pediátrico
}

\author{
ANDRÉS SALAZAR S.*, DIEGO BAZÁES N.** y CRISTIÁN GARCÍA B.***
}

Pediatric radiological clinical case

\section{Historia clínica}

Paciente de sexo masculino, de 18 meses de edad, con antecedentes de haber presentado repetidos cuadros de infecciones respiratorias bajas. A los 16 meses de edad es hospitalizado por neumopatía por Adenovirus, que requirió ventilación mecánica no invasiva. Es dado de alta a los 10 días, con indicación de oxígeno domiciliario, tratamiento con fluticasona, montelukast, cetirizina y prednisona. Durante su hospitalización, se solicitaron tres radiografías $(\mathrm{Rx})$ de tórax, que mostraron opacidades intersticiales en ambos pulmones, sin zonas de condensación alveolar. Se descartó fibrosis quística o una inmunodeficiencia. Al momento del alta se solicitó nueva $\mathrm{Rx}$ de tórax (Figura 1).

Posteriormente es evaluado en la consulta ambulatoria de neumología pediátrica por persistencia de disnea de medianos esfuerzos y tos seca. Una vez descartada una intercurrencia infecciosa, se solicitó Tomografía Computada (TC) de tórax, con cortes de alta resolución, en inspiración (Figura 2a) y espiración (Figura 2b).

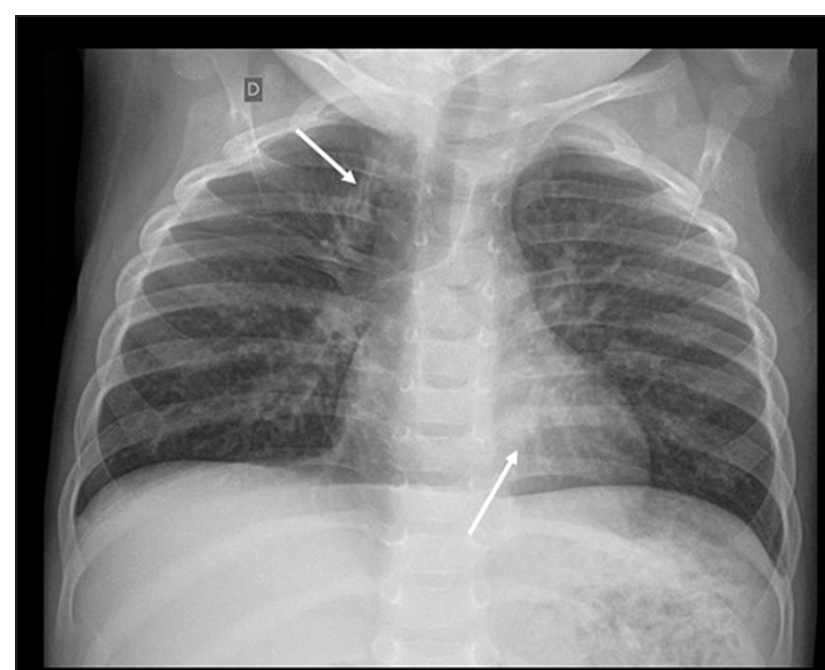

a

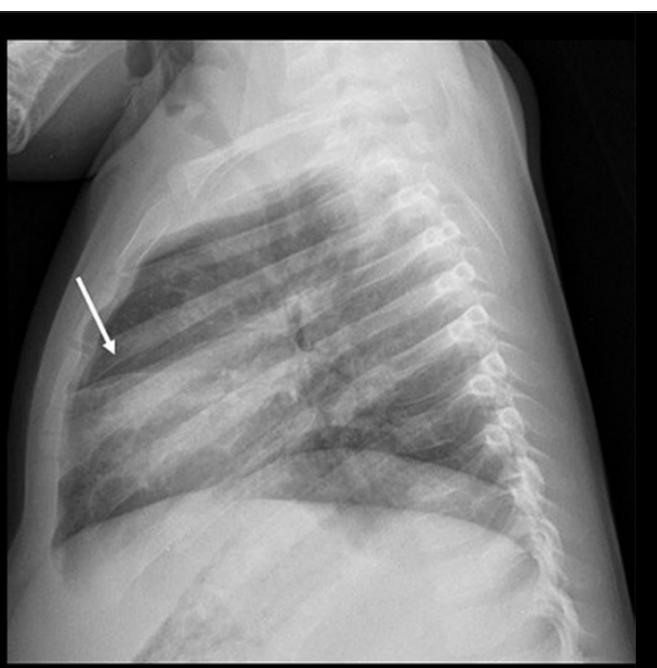

b

Figura 1.

\footnotetext{
* Becado de Subespecialidad en Radiología Pediátrica, Departamento de Radiología, Facultad de Medicina, Pontificia Universidad Católica de Chile. Santiago, Chile.

** Interno $7^{\circ}$ año, Facultad de Medicina, Pontificia Universidad Católica de Chile. Santiago, Chile.

***Departamento de Radiología, Facultad de Medicina, Pontificia Universidad Católica de Chile. Santiago, Chile.
} 


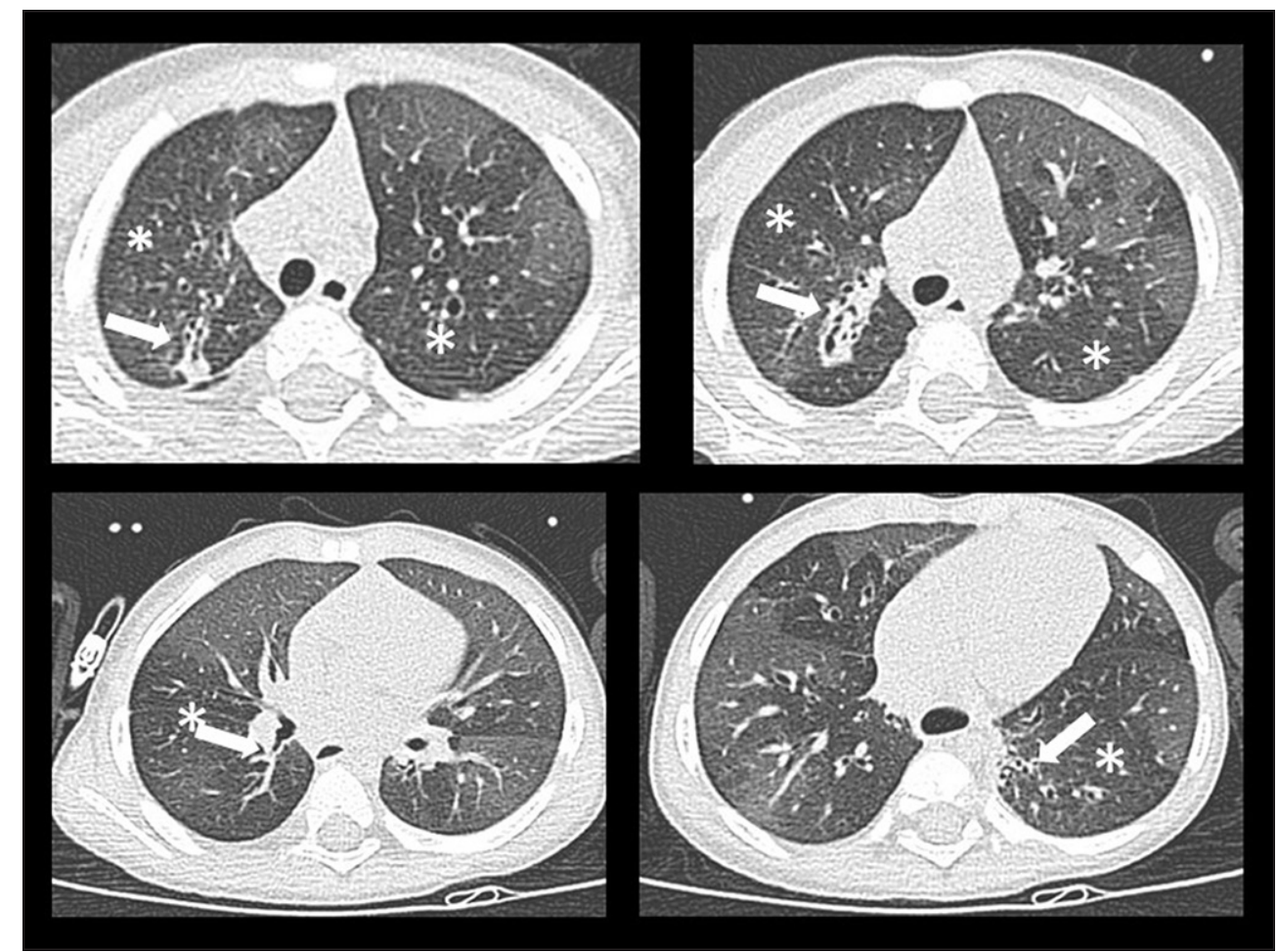

Figura 2a. Inspiración.

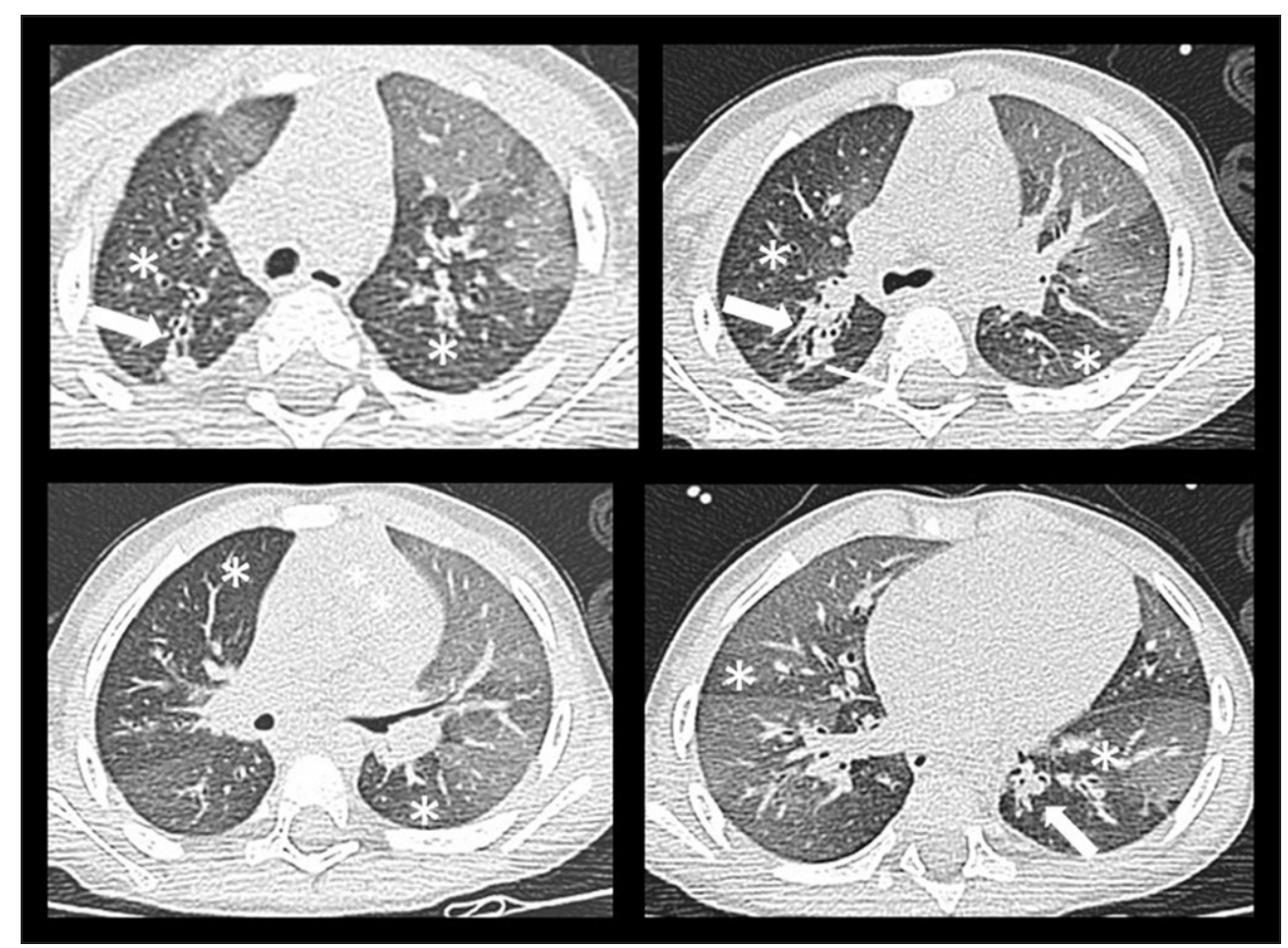

Figura 2b. Espiración.

¿Cuál es su diagnóstico? 


\section{Hallazgos}

- La Rx de tórax (Figura 1) muestra imágenes intersticiales centrales en ambos pulmones y zonas de atelectasia sub-segmentaria en ambos lóbulos inferiores, lóbulo superior derecho y lóbulo medio (flechas). No se demuestra una condensación pulmonar de aspecto neumónico. Estos hallazgos son inespecíficos, pero compatibles con una infección viral.

- La TC de tórax (Figura 2), con cortes axiales en inspiración (2a) y espiración (2b), muestra áreas parcheadas de menor densidad en ambos pulmones $(*)$, con vasos de menor calibre y configuración "en mosaico", lo que se acentúa en los cortes efectuados en espiración (*). Además, se observan bronquiectasias cilíndricas centrales en las áreas comprometidas en ambos pulmones (flechas).

En el contexto clínico de este niño, estos hallazgos son compatibles con una bronquiolitis obliterante postinfecciosa.

\section{Discusión}

La bronquiolitis obliterante (BO) corresponde a una patología infrecuente, donde existe compromiso de la vía aérea terminal como consecuencia de un daño severo y se desarrolla una enfermedad pulmonar obstructiva crónica por obstrucción bronquiolar.

La causa más común de $\mathrm{BO}$ en niños es aquella secundaria a una infección respiratoria baja severa y de estos, en $70 \%$ de los casos se asocia a infección por Adenovirus, seguido por agentes menos comunes como virus respiratorio sincicial, virus Influenza, virus parainfluenza y Mycoplasma pneumoniae entre otros, aunque en estos casos pueden corresponder a una coinfección.

Otra causa de BO es aquella que puede verse en alrededor del $10 \%$ de los pacientes con trasplante de precursores hematopoyéticos o de pulmón ${ }^{1}$.

Dentro de otras causas menos frecuentes, se incluyen enfermedades del tejido conectivo, inhalación de agentes tóxicos (óxido nitroso, amoníaco), reflujo gastroesofágico y Síndrome de Stevens Johnson entre otras etiologías ${ }^{2}$.

En cuanto a la patogenia, la BO se caracteriza por la presencia de una obstrucción parcial o completa de los bronquiolos terminales y respiratorios por tejido fibroso e inflamatorio, que sería secundaria a un daño epitelial de la vía área pequeña, originada por alguna de las etiologías ya mencionadas. Este daño produce una disfunción transitoria de las células epiteliales y/o necrosis tisular local, con producción y acumulación de exudado fibrinopurulento intraluminal en etapas iniciales, donde posteriormente hay depósito de colágeno y otras sustancias.

En etapas más avanzadas de la enfermedad se produce un depósito continuo de colágeno entre el músculo liso y la lámina propia de la pared bronquiolar, provocando una matriz que aumenta progresivamente y provoca estrechamiento y obliteración luminal.

En el caso particular del trasplante pulmonar y de precursores hematopoyéticos, además de lo mencionado, se producen algunas circunstancias especiales, basados en el papel preponderante que tienen los factores aloreactivos y la respuesta inmunológica del paciente, los cuales producen una cascada de eventos que inicialmente muestran características celulares de un rechazo agudo, para finalmente desembocar en los cambios fibroproliferativos de la vía aérea terminal ${ }^{3}$.

La sintomatología clínica que desarrollan los niños con $\mathrm{BO}$ post infecciosa es inicialmente similar a la de un episodio agudo de neumopatía viral, con fiebre, tos y sibilancias en algunos casos, desarrollando posteriormente disnea progresiva, la cual se reconoce como uno de los síntomas de presentación habitual. Una vez establecido y desarrollado el compromiso de la vía aérea pequeña se produce taquipnea, retracción intercostal/subcostal, aumento en el diámetro anteroposterior del tórax, crépitos e hipoxemia, la cual puede persistir por varias semanas a pesar del manejo con oxígeno suplementario.

Las manifestaciones clínicas pueden prolongarse por varios meses, con un curso fluctuante y episodios recurrentes de neumonía y/o atelectasia. La recuperación incompleta es frecuente en estos pacientes, lo que se asocia a consultas y hospitalizaciones repetidas ${ }^{2,4}$.

El diagnóstico se basa principalmente en la historia clínica, el examen físico, detección del germen causal, estudios de función pulmonar, Los estudios de imágenes y ocasionalmente la biopsia pulmonar.

Las pruebas de evaluación de la función pulmonar en niños con BO típicamente muestran una severa obstrucción fija al flujo aéreo, con disminución de la compliance (distensibilidad) pulmonar, aumento de la resistencia de vías aéreas con escasa respuesta a broncodilatador. En niños mayores se hace evidente una típica disminución del volumen espiratorio forzado en el 1er segundo $\left(V_{E F}\right)$ y signos concordantes con una severa obstrucción de vía aérea, predominantemente 
pequeña, así como también alteraciones que sugieren hiperinsuflación y atrapamiento aéreo ${ }^{4}$.

\section{Estudios de imágenes}

Los estudios de imágenes tienen un importante papel en el diagnóstico de BO, en especial cuando los hallazgos se evalúan en conjunto con la información clínica y los exámenes de laboratorio y permiten orientar respecto a la extensión del compromiso pulmonar.

La Rx de tórax muestra alteraciones inespecíficas y los hallazgos dependerán de la severidad de la enfermedad. Los hallazgos más comunes son engrosamiento del intersticio peribronquial generalmente de predominio central e hiperinsuflación pulmonar (Figura 1). La hiperinsuflación se manifiesta como zonas de mayor transparencia $y$ aumento de volumen pulmonar, en una extensión y distribución variable. También pueden verse zonas de atelectasia segmentaria o subsegmentaria. En cerca de un tercio de los niños con $\mathrm{BO}$ post infecciosa, en la Rx de tórax puede observarse un pulmón hiperlúcido unilateral por hiperinsuflación asimétrica, sin compromiso evidente del pulmón pulmonar contralateral, condición conocida como Síndrome de Swyer-James ${ }^{2,4}$. La sensibilidad de la Rx de tórax es baja en la detección de bronquiectasias, que con frecuencia acompañan a esta enfermedad.

La TC de tórax utiliza radiación ionizante y en niños debe usarse con protocolos de baja dosis, por ser más radiosensibles y por su mayor expectativa de vida, considerando que los efectos nocivos pueden ocurrir muchos años más tarde 4 . Puede requerir sedación y en el caso de la BO, no es necesario el uso de medio de contraste endovenoso. Debe efectuarse con cortes de alta resolución durante inspiración y espiración y puede mostrar hallazgos característicos de BO, evitando así la necesidad de biopsia pulmonar en la mayoría de los pacientes. Estos consisten fundamentalmente en: engrosamiento del intersticio peribronquial, patrón de atenuación "en mosaico", bronquiectasias cilíndricas centrales en las zonas comprometidas, áreas de atelectasia o de neumopatía crónica, opacidades centrolobulillares (Figura 2).

El patrón de atenuación en mosaico, es un hallazgo habitual y característico en la $\mathrm{BO}$ post infecciosa y se manifiesta como pulmones heterogéneos, con zonas de distinta densidad o atenuación del parénquima pulmonar de distribución variable, generalmente bilateral, con áreas de parénquima comprometido, alternadas con zonas de parénquima conservado. Es secundario a la vasoconstricción, que se produce en algunas áreas de parénquima pulmonar por hipoxia tisular, como manifestación de un shunt o cortocircuito vascular desde el pulmón hipoventilado hacia áreas de ventilación normal o hiperventiladas. Esto explica el hallazgo de oligohemia y disminución de calibre de vasos pulmonares en las zonas afectadas ${ }^{4-6}$. El hallazgo de imágenes de atrapamiento aéreo en las zonas comprometidas, constituye el principal predictor de limitación del flujo aéreo y es un hallazgo clave en BO y destaca especialmente en espiración, por lo que puede ser subdiagnosticado en estudios habituales, que incluyen cortes realizados solo en inspiración. Esto ocurre porque en pacientes con enfermedad de la vía aérea pequeña, el aire no puede escapar fácilmente en las zonas obstruidas, por lo que la atenuación de los segmentos involucrados permanece relativamente sin cambios en comparación con la de las imágenes inspiratorias.

En relación con los pacientes sometidos a trasplante pulmonar se describe el desarrollo de un síndrome de bronquiolitis obliterante (SBO). Considerando la imposibilidad de biopsia en el pulmón trasplantado, el diagnóstico se base principalmente en la disminución de $\mathrm{VEF}_{1}$ mayor a un $80 \%$, excluyendo otras causas de esta alteración, tales como infecciones, rechazo o estenosis anastomótica. Los hallazgos en la TC incluyen dilatación bronquial, engrosamiento parietal bronquial, patrón de perfusión en mosaico y atrapamiento aéreo en cortes espiratorios ${ }^{5}$. Este último signo es el que ha demostrado la mejor correlación y constituye el principal hallazgo en los pacientes con SBO con trasplante pulmonar y también en los sometidos a trasplante de precursores hematopoyéticos ${ }^{6}$.

En cuanto al pronóstico, en BO post infecciosa secundaria a adenovirus, la mortalidad en la infección aguda es variable, pero puede alcanzar hasta el $15 \%$. Una vez establecida la BO, la tasa de mortalidad es baja. Sin embargo, la morbilidad asociada es elevada, con frecuentes hospitalizaciones por infecciones respiratorias y cuadros bronquiales obstructivos. Esto suele mantenerse durante los primeros años, con mejoría clínica y disminución de exacerbaciones en los años subsecuentes. Sin embargo, los estudios funcionales y exámenes imagenológicos suelen mantenerse alterados ${ }^{4}$.

En los pacientes trasplantados con BO el pronóstico es incierto, tanto en morbilidad como en mortalidad, ya que la velocidad en el deterioro de la función pulmonar muestra alta variabilidad. Algunos muestran un compromiso rápido y 
progresivo con una alta tasa de mortalidad. Otro grupo evoluciona a menor velocidad y puede desarrollar una obstrucción severa de vía aérea con colonización bacteriana crónica en un alto porcentaje de pacientes ${ }^{3}$.

En resumen, la BO es una patología infrecuente cuya etiología principal es la post infecciosa. Es de vital importancia su reconocimiento precoz, considerando su evolución hacia una patología pulmonar obstructiva crónica en la mayor parte de los casos, lo que produce un importante deterioro en la calidad de vida del niño, con múltiples hospitalizaciones y exacerbaciones respiratorias, además de un pronóstico incierto.

$\mathrm{Su}$ diagnóstico se basa en una estricta correlación de los antecedentes clínicos, los hallazgos del examen físico, pruebas funcionales respiratorias y exámenes complementarios, dentro de los cuales los estudios de imágenes, especialmente la $\mathrm{TC}$, tienen una importancia preponderante.

Es importante tener en consideración otras etiologías, entre las que destaca la patología secundaria a trasplante de precursores hematopoyéticos, lo cual nos permitirá, en este subgrupo de pacientes, un seguimiento y control estricto de su función respiratoria.

\section{Bibliografía}

1.- PIPAVATH SJ, LYNCH DA, COOL C, BROWN KK, NEWELL JD. Radiologic and pathologic features of bronchiolitis. AJR Am J Roentgenol. 2005; 185: 354-63.

2.- MOONNUMAKAL SP, FAN LL. Bronchiolitis obliterans in children. Curr Opin Pediatr. 2008; 20: 272-8.

3.- KURLAND Q, MICHELSON P. Bronchiolitis obliterans in children. Pediatr Pulmonol. 2005; 39: 193-208.

4.- FISCHER GB, SARRIA EE, MATTIELlO R, MOCELIN HT, CASTRO-RODRIGUEZ JA. Post infectious bronchiolitis obliterans in children. Paediatr Respir Rev. 2010; 11: 233-9.

5.- PIPAVATH SJ, LYNCH DA, COOL C, BROWN KK, NEWELL JD. Radiologic and pathologic features of bronchiolitis. Am J Roentgenol. 2005; 185: 354-63.

6.- GUNN ML, GODWIN JD, KANNE JP, FLOWERS ME, CHIEN JW. High-resolution CT findings of bronchiolitis obliterans syndrome after hematopoietic stem cell transplantation. J Thorac Imaging. 2008; 23: $244-$ 50 .
Correspondencia a:

Dr. Cristián García Bruce

Departamento de Radiología, Facultad de Medicina,

Pontificia Universidad Católica de Chile.

Email: cgarciab@uc.cl 